\title{
Changes in Tyrosine Transaminase and Phosphoenolpyruvate Kinase Activities during Short Term Incubation of Fetal Liver
}

\author{
LORNE KIRBY AND PETER HAHN(17) \\ Department of Paediatrics and Obstetrics and Gynaecology, University of British Columbia, Vancouver, \\ British Columbia, Canada
}

\section{Extract}

Rat fetal livers were homogenized and incubated for up to 3 hr in Eagle's medium. Both phosphoenolpyruvate carboxykinase (PEPK) and tyrosine transaminase (TTA) activities in the high speed supernatant increased 5 -fold and $\mathbf{1 0}$-fold, respectively, during incubation. Neither cycloheximide nor actinomycin $D$ inhibited this rise in activity. Inasmuch as no change in activity during incubation was found in the whole homogenate, it is concluded that a redistribution of the enzyme occurs between cell fractions.

\section{Speculation}

It is suggested that the initial increase in TTA and PEPK activities in the liver very soon after birth may be due to release of preformed enzyme from polysomes and that this triggers a sequence of events leading to new enzyme synthesis.

It has been shown that during in vitro incubation of fetal rat and human liver there is a spontaneous increase in the activities of tyrosine transaminase (EC. 2.6.1.5) and phosphoenolpyruvate kinase (EC. 4.1.1.32) $(7,9,12)$. This commences $30 \mathrm{~min}$ after the start of incubation and continues for at least $24 \mathrm{hr}$. No other enzymes studied show this kind of change. Inasmuch as the increase over the first 2-4 hr of incubation cannot be suppressed by cycloheximide or actinomycin D, although the subsequent further rise is susceptible to inhibition by these drugs (7), we suggested that the initial increase is not due to new enzyme synthesis.

In this paper the initial rise in the activities of these two enzymes is further studied.

\section{MATERIALS AND METHODS}

Chemicals were obtained from Sigma Chemical Co. (14). Radioactive bicarbonate (specific activity $100 \mu \mathrm{Ci} / \mathrm{mmol}$ ) from Amersham/Searle (15).

Livers were collected from rat fetuses aged 19-21 days. Freshly collected tissue was cut into pieces and homogenized with 5 times its volume of Eagle's minimum essential medium with Earle's balanced salt solution using a glass homogenizer and a Teflon pestle. The homogenate was placed into plastic centrifuge tubes fitted with screw caps. A mixture of $95 \%$ oxygen and $5 \% \mathrm{CO}_{2}$ was bubbled through the tubes for $1 \mathrm{~min}$. They were then closed and incubated at $37^{\circ}$ in a water bath shaker for various time periods.

Enzyme activities were determined in the whole homogenate, the nuclear fraction, the mitochondrial fraction $(10,000 \times g$ for 15 $\mathrm{min}$ ), and the $100,000 \times g$ for $60 \mathrm{~min}$ supernatant and pellet. The nuclear fraction was purified on a sucrose gradient according to the method of Maggio et al. (8). The purity of the fractions was assessed microscopically and TTA and PEPK were assayed as described previously (7). Initially experiments were done under sterile conditions. However, no differences were found if sterility was not strictly observed in subsequent work.

\section{RESULTS}

It was argued that because enzyme activities increase during the first $2-4 \mathrm{hr}$ in incubated liver pieces and because this increase is not inhibited by inhibitors of proteosynthesis, a rise should also be observed in incubated homogenates. Figure 1 shows that both TTA and PEPK activities in the $100,000 \times g$ for 45 min supernatant prepared from homogenates incubated for various lengths of time increase by a factor of 5-10 within $2 \mathrm{hr}$. This is not because of a change in protein concentration. During incubation the protein concentration of all fractions never changed more than by $10 \%$.

However, if enzyme activities are determined in whole homogenate, no changes with time of incubation are observed. These findings suggested redistribution of the enzymes within the cell fractions during incubation. Hence, activities were determined in the various fractions in fetal and postnatal livers. It is apparent from Figure 2 that age differences are more pronounced in the high speed supernatant fraction than in any other isolated part of the cell. This is particularly striking in the case of TTA. Hardly any activity is found in the high speed supernatant fraction from fetal liver. In postnatal liver this fraction is about 50 -fold more active. In contrast, the pellet obtained from this supernatant fraction contains only twice as much activity postnatally as it does prenatally. No activities were found in the purified nuclear fraction.

It would seem then that during incubation of tissue pieces or homogenate, enzyme is released from a cellular fraction into the high speed supernatant, in which activities are usually determined. To test this further, liver homogenates were incubated for up to 2 $\mathrm{hr}$ and enzyme activities were determined in the various cell fractions at the end of incubation. Figure 3 shows that changes are most pronounced for TTA during the first $90 \mathrm{~min}$ of incubation. During that time, activity in the high speed supernatant increases from nearly 0 to about $0.4 \mu \mathrm{g} / \mathrm{min} / \mathrm{mg}$ protein whereas in the pellet of the same homogenate a considerable decrease in specific activity is observed. Further evidence for this release of TTA comes from the fact that incubation of the supernatant alone for 90 min causes no change in activity.

In the case of PEPK, similar changes are observed (Fig. 3). However, the decrease in activity of the pellet during incubation is less pronounced than for TTA; perhaps because enzyme activity becomes assayable only after release.

Neither cycloheximide nor actinomycin $D$ in concentrations used previously (7) inhibited the rise in enzyme activity in the supernatant fraction after incubation of the whole rat liver homogenate. Incubation of the homogenate for $19 \mathrm{hr}$ resulted in a slight decrease in TTA activity in the supernatant, whereas PEPK activity disappeared completely (Fig. 4). This change was not affected by addition of glucagon $\left(5 \times 10^{-5} \mathrm{M}\right)$ or cycloheximide at the start of incubation. 
We have shown previously (5) that, in contrast to fetal liver, incubation of postnatal rat liver pieces at $37^{\circ}$ leads to a decrease in PEPK activity. Incubation of postnatal liver homogenates for 90 min had no effect whatsoever on the distribution of PEPK or TTA nor did it cause a rise in enzyme activity in the high speed supernatant (Table 1).

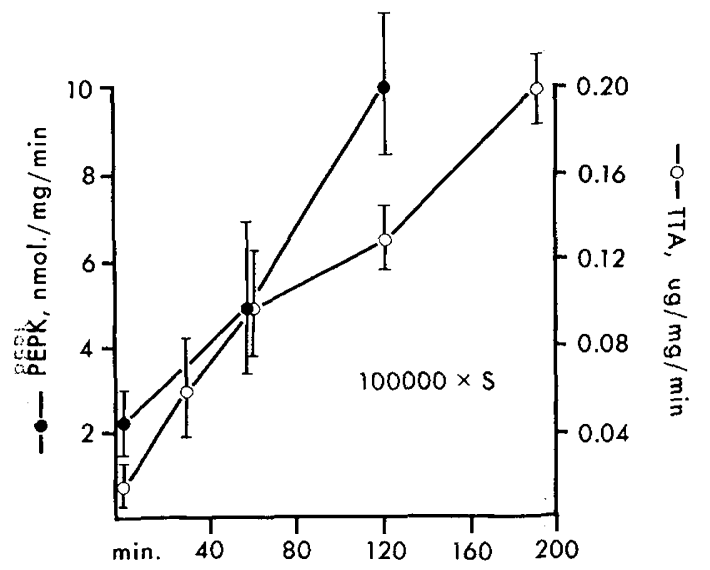

Fig. 1. Phosphoenolpyruvate kinase $(P E P K)$ and tyrosine transaminase $(T T A)$ activities in the $100,000 \times g$ for 45 min supernatant prepared from fetal rat liver homogenates incubated for various time periods (abscissa). Each point is the mean of 10 samples $\pm \mathrm{SE}$ (vertical bars).
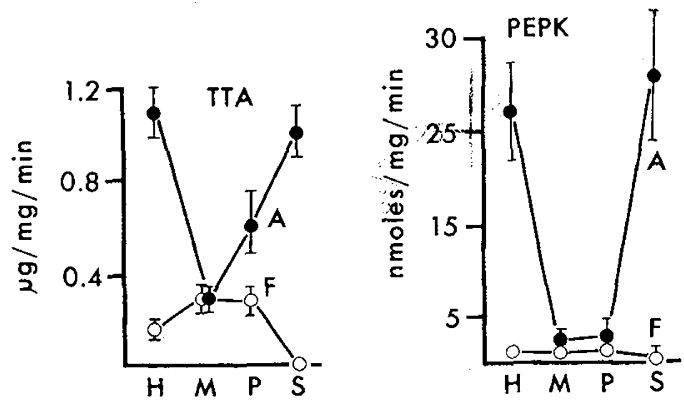

Fig. 2. Phosphoenolpyruvate kinase $(P E P K)$ and tyrosine transaminase $(T T A)$ activities in fetal $(F, O)$ and adult $(A, 0)$ rat liver fractions. $H$ : homogenate; $\boldsymbol{M}$ : mitochondrial fraction; $P$ : pellet from $100,000 \times g$ spin; $\mathrm{S}$ : supernatant from $100,000 \times g$ spin. Each point is the mean of eight samples $\pm \mathrm{SE}$ (vertical bars). The $\mathrm{M}$ and $\mathrm{P}$ fractions were suspended in the same amount of buffer as was used for the first homogenization.

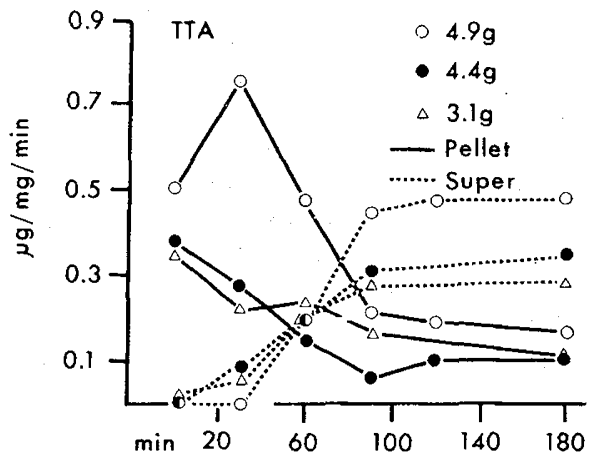

\section{DISCUSSION}

The incubation of fetal liver homogenates and the determination of enzyme activities in the various cell fractions at the end of incubation enabled us to show that the initial increase in the activities of PEPK and TTA is not due to new proteosynthesis. This had been suggested previously (7). This technique also showed

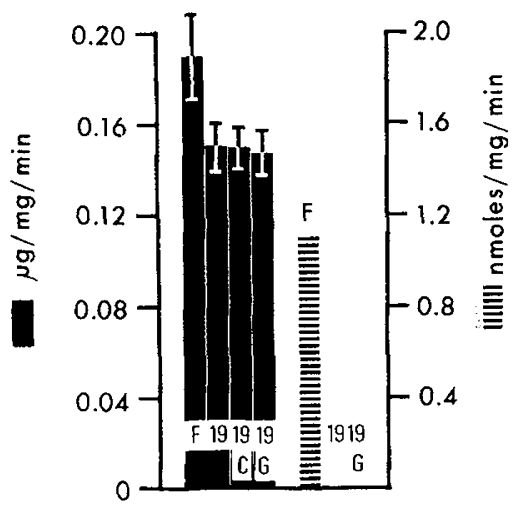

Fig. 4. Tyrosine transaminase (black) and phosphoenolpyruvate kinase (horizontal lines) activities in the $100,000 \times g$ for 45 min supernatant of fetal rat liver homogenates incubated for $19 \mathrm{hr} . F$ : fresh tissue. Activity determined immediately after death. 19: activity after $19 \mathrm{hr}$ of incubation; $19 \mathrm{C}$ : activity after $19 \mathrm{hr}$ of incubation in the presence of cycloheximide (1 $\left.\times 10^{-5} \mathrm{M}\right) ; 19 \mathrm{G}$ : the same in the presence of glucagon $\left(5 \times 10^{-5} \mathrm{M}\right)$. Note total disappearance of phosphoenolpyruvate kinase. Ten samples per column $\pm \mathrm{SE}$.

Table 1. Effect of incubating liver homogenates obtained from rats aged 30 days on enzyme activities in $100,000 \times g$ supernatant ${ }^{1}$

\begin{tabular}{|c|c|c|c|}
\hline \multirow[b]{2}{*}{ Enzyme } & \multicolumn{2}{|c|}{ Incubation } & \multirow[b]{2}{*}{ Units } \\
\hline & Before & After & \\
\hline TTA & $2.0 \pm 0.4$ & $2.1 \pm 0.35$ & $\mu \mathrm{g}$ PHPP $/ \mathrm{mg}$ protein $/ \mathrm{min}(6)$ \\
\hline PEPK & $10.2 \pm 4.0$ & $9.8 \pm 3.20$ & $\mathrm{nmol} / \mathrm{mg}$ protein $/ \mathrm{min}(4)$ \\
\hline
\end{tabular}

${ }^{1}$ Enzyme activities were determined in the high speed supernatant of liver homogenates at the start of the experiment and after $90 \mathrm{~min}$ of incubation of the whole homogenate at $37^{\circ}$. Means $\pm \mathrm{SE}$; number of experiments in parentheses. TTA: tyrosine transaminase; PEPK: Phosphoenolpyruvate carboxykinase.

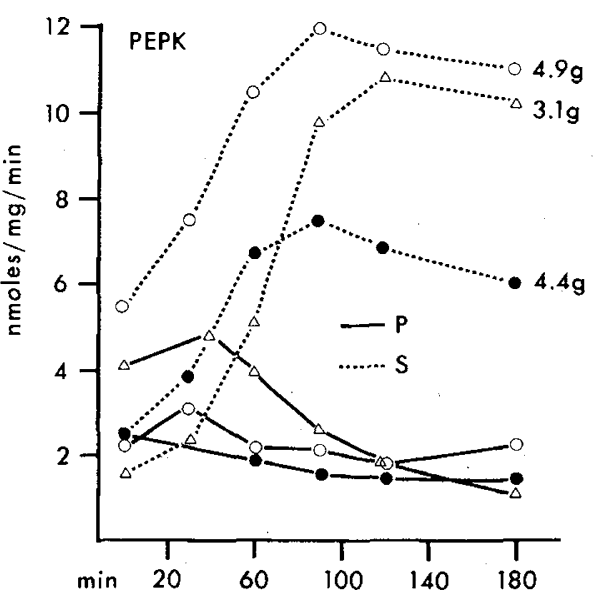

Fig. 3. Changes in phosphoenolpyruvate kinase $(P E P K)$ and tyrosine transaminase $(T T A)$ activities in the $100,000 \times g$ for 45 min supernatant and pellet prepared from fetal rat liver homogenates incubated for various time periods. Data for three litters. Mean body weights are given in the figure. 
that, under our conditions, the cell has to be intact for new enzyme synthesis to occur, since even after $19 \mathrm{hr}$ of incubation of the homogenate, no increase in activities was observed. In fact PEPK activity disappeared completely. In contrast, incubation of liver pieces for $19 \mathrm{hr}$ resulted in new enzyme synthesis, since the rise in activity could be blocked with actinomycin D (1). Furthermore, the incubation of the high speed supernatant alone revealed that neither enzyme is activated in vitro. Our data indicate that the most probable explanation for the rise of both enzyme activities during short term incubation of fetal rat liver is a redistribution of preformed enzyme, which presumably exists in a "nascent" form bound to polysomes (microsomes) and is released into the cytoplasm under appropriate conditions. This has been shown to be the case for neonatal TTA in rat liver (2), but also for fetal rat liver (7).

It has been well established that de novo synthesis of both enzymes occurs both in vitro and in vivo in response to hormones (12) and parturition $(4,13)$. It has also been shown that the rate of PEPK breakdown is considerably reduced during periods of rapid enzyme synthesis (6).

Our data lead us to suggest that the initial rapid increase in PEPK and TTA activities in fetal livers in vitro is due to a release of preformed enzyme which is then followed by de novo synthesis. It is attractive to speculate that at birth a similar sequence of events occurs, i.e., enzyme release followed by new enzyme synthesis. When fetal rat liver is placed into the incubation medium, the level of cyclic AMP in the tissue rises rapidly (3). Similarly, after delivery, the cyclic AMP concentration in rat liver rises (10). Since cyclic AMP is known to lead to increased phosphorylation of ribosomes (1), this may lead to release of specific enzymes into the cytoplasm, thus making more ribosomes available for mRNA. It is possible that the changed mRNA concentration in the cytoplasm or nucleus is then the actual stimulus for further enzyme synthesis.

It should also be mentioned that TTA can be released from microsomes not only by cyclic AMP but also by fatty acids and acyl-CoA (7).

\section{SUMMARY}

Incubation of fetal rat liver homogenates at $37^{\circ}$ for $2-3 \mathrm{hr}$ increased PEPK activity in the $100,000 \times g$ supernatant 5 -fold and
TTA activity 10 -fold. At the same time, activity in the $100,000 \times g$ pellet decreased and no change was observed in the whole homogenate. It is concluded that during incubation of fetal liver pieces or homogenates in vitro, a redistribution of enzymes occurs between cell particles and cell sap. It is suggested that release of enzyme into the cell sap may be the first stimulus for subsequent enzyme synthesis which occurs after birth.

\section{REFERENCES AND NOTES}

1. Blat, C., and Loeb, J. E.: Effect of glucagon on phosphorylation of some rat liver ribosomal protein in vivo. Fed. Eur. Biochem. Soc. Lett., 18: 124 (1971).

2. Chuah, C. C., and Oliver, I. T.: Role of adenosine cyclic monophosphate in the synthesis of tyrosine amino transferase in neonatal rat liver: Release of enzyme from membrane bound polysomes in vitro. Biochemistry, 10: 2990 (1971).

3. Dodek, P., Kirby, L., Frohlich, J., Hahn, P., and Ho-Yuen, B.: High glucose concentration and PEPK activity in human and rat liver cultures (In press).

4. Greengard, O.: The hormonal regulation of enzymes in prenatal and postnatal rat liver. Biochem. J., 115: 19 (1969)

5. Hahn, P., Kirby, L., and Frohlich, J.: Hormonal regulation of enzyme activities in rat and human fetal tissues. In: P. L. Morselli, S. Garattinin, and F. Sereni: Basic and Therapeutic Aspects of Perinatal Pharmacology, p. 215 (Raven Press, New York, 1975).

6. Hanson, R. W., Fisher, L., Ballard, F. J., and Reshef, L.: The regulation of phosphoenolpyruvate carboxykinase in fetal rat liver. Enzyme, 15: 97-110 (1973).

7. Kirby, L., and Hahn, P.: Enzyme activities during culturing of fetal rat liver. Can. J. Biochem., 51: $476(1973)$.

8. Maggio, R., Siekevitz, P., and Palade, G. E.: Studies on isolated nuclei: Isolation and chemical characterization of a nuclear fraction from guinea pig liver. J. Cell Biol. 18: 267 (1963).

9. Mandelli, M., Piceni-Sereni, L., and Sereni, F.: Spontaneous dévelopment of cytosolic phosphoenopyruvate carboxylase in foetal rat liver cultures. Biochim. Biophys. Acta, 309: 519 (1973).

10. Novak, E., Drummond, G. I., Skala, J., and Hahn, P.: Developmental changes in cyclic AMP, protein kinase, phosphorylase kinase and phosphorylase in liver, heart and skeletal muscle of the rat. Arch. Biochem. Biophys., 150: 511 (1972).

11. Sereni, F., and Sereni, L. P.: Spontaneous development of tyrosine transaminase activity in fetal liver cultures. Advan. Enzyme Regul., 8: 253 (1970).

12. Wicks, W. D.: Regulation of hepatic enzyme synthesis by cyclic AMP. Ann. N. Y. Acad. Sci., 185: 152 (1971).

13. Yeung, D., and Oliver, I. T.: Gluconeogenesis from amino-acids in neonatal rat liver. Biochem. J., 103: 744 (1967).

14. Sigma Co., St. Louis, Mo.

15. Amersham/Searle Corp., Oakville, Ont.

16. This research was supported by the Medical Research Council (Canada).

17. Requests for reprints should be addressed to: P. Hahn, M.D., Centre for Developmental Medicine, 811 W. 10th Ave., Vancouver, B.C. V5Z IL7 (Canada).

18. Accepted for publication November 17, 1975. 